\title{
Reproductive and energetic costs of injury in the mangrove tree crab
}

\author{
Blaine D. Griffen ${ }^{1, *}$, Zachary J. Cannizzo ${ }^{2}$, Jade Carver $^{1}$, Morgan Meidell ${ }^{1}$ \\ ${ }^{1}$ Biology Department, Brigham Young University, Provo, UT 84602, USA \\ ${ }^{2}$ National Oceanic and Atmospheric Administration Office of National Marine Sanctuaries - National Marine \\ Protected Areas Center, Silver Spring, MD 20910, USA
}

\begin{abstract}
Nonlethal injury is a common and ubiquitous feature of marine systems and can result in altered growth and survival rates. Ecological theory predicts that injured animals should face an energetic tradeoff between investing in recovery vs. investing in reproduction. Possible impacts on reproduction may range in magnitude from very strong (elimination of reproduction), to intermediate (reduced number of offspring), to weak (reduced investment in each offspring). While this tradeoff is well established in terrestrial systems, it has received little attention in the marine environment, particularly in a way that quantitatively relates the degree of injury to the degree of reproductive impact. We examined injury via limb loss across 4 sites in the mangrove tree crab Aratus pisonii. We found that limb loss was highest at the site that was closest to roads and had the highest level of human presence, and conversely, injury was lowest at the site furthest from the road and with the lowest level of human presence. We found evidence that the quality of consumed food likely decreases with the number of limbs lost, but found no influence of limb loss on amount of food consumed or on energy storage. We show that limb loss reduced the number of eggs produced and that the mass of the ovary declined with the number of regenerating limbs, providing direct evidence for a tradeoff between reproduction and injury recovery. Further, our study therefore suggests that these impacts may increase with the level of human disturbance.
\end{abstract}

KEY WORDS: Aratus pisonii $\cdot$ Autotomy $\cdot$ Energy budget $\cdot$ Fecundity $\cdot$ Trade-offs

\section{INTRODUCTION}

Limb loss and other forms of nonlethal injury are ubiquitous in marine organisms (Lindsay 2010). At times, injury is a result of nonlethal predation (Peterson \& Quammen 1982). At other times, it is purposeful and is under organismal control (i.e. autotomy). For instance, anemones can autotomize tentacles (e.g. Purcell 1977), polychaete worms drop whole body segments (e.g. De Vlas 1979), nudibranchs can shed dorsal papillae (e.g. Miller \& Byrne 2000), cephalopods can drop arms (e.g. Caldwell 2005), crustaceans autotomize claws or walking legs (reviewed in Juanes \& Smith 1995), and echinoderms shed arms (Bingham et al. 2000) and internal organs

\footnotetext{
${ }^{*}$ Corresponding author: blaine_griffen@byu.edu
}

(e.g. García-Arrarás et al. 1999). Whether purposeful or not, nonlethal injury is not only taxonomically widespread, but is also often prevalent within populations. For example, Juanes \& Smith (1995) reviewed limb loss in decapod crustaceans and found that in some populations, injured animals can make up as much as $80 \%$ of the population. Over all crustacean populations examined, approximately $25 \%$ of individuals were missing at least $1 \mathrm{limb}$. When these patterns are broadened to include all marine invertebrate taxa, the average incidence of injury is much higher, with nearly $43 \%$ of individuals in a population injured at any one time (Lindsay 2010). Thus, injury is a ubiquitous stressor with which marine organisms must cope.

() B. D. Griffen, J. Carver, M. Meidell and, outside the USA, the US Government 2020. Open Access under Creative Commons by Attribution Licence. Use, distribution and reproduction are unrestricted. Authors and original publication must be credited.

Publisher: Inter-Research · www.int-res.com 
While often yielding the positive benefits of predator escape (Wasson et al. 2002, Cooper \& Frederick 2009) and expulsion of wounded body parts (reviewed in Fleming et al. 2007), limb loss can have a range of detrimental impacts on individual organisms. These include altered mobility (e.g. Gerald \& Thiesen 2014, Duermit et al. 2017), reduced foraging success (e.g. Diaz-Guisado et al. 2006, Barrios et al. 2008, Tummon Flynn et al. 2015), increased metabolic expenditures (Mcgaw 2006), altered anti-predator behavior (Fleming et al. 2007), reduced competitive abilities (e.g. Smith 1992, Daleo et al. 2009), decreased survival (e.g. Gandy et al. 2016, Duermit et al. 2017), and impaired reproductive success (e.g. Bingham et al. 2000, Barrios et al. 2008). Many of these costs are a consequence of altered capabilities due to the injury. For example, altered mobility may result from the loss of balance or the loss of walking legs (Gerald \& Thiesen 2014). Similarly, reduced foraging results from increased difficulty in handling food with fewer appendages (Hogan \& Griffen 2014, Hancock \& Griffen 2017) or regenerated appendages that are not as strong as the originals (Brock \& Smith 1998).

Other costs are the result of tradeoffs that are imposed by a limited supply of resources and the need to distribute those resources as efficiently as possible. For instance, reduced foraging following injury results in limited growth or reproductive capabilities due to energy limitation (Diaz-Guisado et al. 2006). Thus, injured organisms must make the physiological choice between expending energy to regenerate the lost/damaged appendage or expending energy on reproduction. Ecological theory predicts that evolution should yield strategies that move organisms towards optimal performance (Stearns 1989). It has been hypothesized that this should lead to a tradeoff where organisms reproduce less in order to, instead, allocate that energy for regenerating the injured/lost body part (Juanes \& Smith 1995, Emberts et al. 2019). Theoretical work based on tail autotomy in lizards and salamanders predicts that this tradeoff following limb loss may decrease reproduction to different degrees (Bernardo \& Agosta 2005). The strongest effect is an entire loss of reproductive effort as all resources are instead diverted to limb regeneration. This strongest effect should be expected when limb loss reduces survival for long-lived species (see references and review in Bernardo \& Agosta 2005). The intermediate response to limb loss often takes the form of reduced number of propagules produced, a response that still allows for reproduction, but directly reduces the reproductive success of the mother (e.g. Barrios et al.
2008). The weakest response is a decrease in the perpropagule investment by the mother, leading to lower-quality offspring. This is a form of maternal effect (i.e. the condition of the mother influences the condition of the offspring; Kirkpatrick \& Lande 1989) that does not directly reduce reproductive success of the mother but can negatively influence the fitness of the offspring, thereby reducing the inclusive fitness of the mother (e.g. Schwagmeyer \& Mock 2008). These responses may not be independent, but could occur sequentially or even simultaneously in the same individual, depending on the timing of injury relative to energy commitment to the reproductive process (Maginnis 2006). Further, these second and third categories (reduced number of offspring and reduced investment in each offspring) are graded responses that should be expected to increase with the magnitude of the injury (Bernardo \& Agosta 2005). However, there are few clear demonstrations that these hypothesized tradeoffs occur. Rather, most studies that have examined the impacts of limb loss on reproduction have treated injury as a binary factor (yes/no), rather than as a continuous factor expressed by different numbers of lost limbs (Bernardo \& Agosta 2005).

Decapod crustaceans play an important role in coastal oceans, both ecologically (Boudreau \& Worm 2012) and economically (e.g. Donihue 2018), and are becoming more important with the decline of finfish due to overfishing in many areas (Steneck 1997, Steneck \& Carlton 2001, Molfese et al. 2014). As cited above, autotomy is common in this group (Juanes \& Smith 1995). Long-term energy for growth and reproduction in crustaceans is generally stored as lipids in the hepatopancreas, a digestive organ (Vonk 1960, Adiyodi 1969). The timing of the use of these lipid stores relative to egg production seems to differ by species (Griffen 2018), but regardless of this, lipids are eventually transferred to the ovary where they are deposited into the eggs during the process of vitellogenesis (Wolin et al. 1973). Growth in this group of species is incremental, occurring with periodic molts (summarized in Warner 1977). Soft tissue from missing limbs is regenerated during intermolt periods, beginning shortly after limb loss and culminating in the appearance of a proecdysial limb bud. Full regeneration of missing limbs takes place at the molt and can require multiple molt cycles to complete (summarized in Hopkins \& Das 2015). This complicates the ability to detect energetic tradeoffs associated with limb regeneration, since the energetic strategy employed by an individual could shift during this relatively long process. 
Previous work demonstrates that limb loss in decapod crustaceans can negatively influence reproductive success. For instance, injured velvet swimming crabs Necora puber with missing limbs produced smaller broods than those with all their limbs (Norman \& Jones 1993). Similarly, declawed stone crabs Menippe spp., in a claw-based fishery in the southeastern United States, produce clutches that are considerably smaller than those produced by crabs that have retained their claws (Crowley et al. 2019). Additionally, in a study of the invasive Asian shore crabs Hemigrapsus sanguineus, gravid individuals had a lower frequency of missing limbs than nongravid individuals (Hobbs et al. 2017). A single study has examined changes in clutch size with differing number of missing limbs. Melville-Smith \& de Lestang (2007) showed that the rock lobster Panulirus cygnus produced progressively smaller clutches with each additional missing limb. Yet, it was not demonstrated whether this decrease in fecundity was due to reduced energy intake in injured animals or altered energy allocation. Thus, despite these demonstrations that limb loss can negatively influence reproductive output, no study has yet demonstrated a clear tradeoff between regeneration of missing limbs and reproduction in crustaceans.

Human impacts may influence the amount of injury as well as the physiological response following injury. Animal injury rates have been shown to increase in areas with high human presence compared to rural settings (Chapple \& Swain 2004, Tyler at al. 2016). This could occur due to changes in the amount of predation pressure or conspecific aggression that are also altered by human influences (e.g. Reichmuth et al. 2009, Kern \& Radford 2016). Additionally, the presence of anthropogenic structures (Cannizzo et al. 2018,2020 ) and other human influences is known to alter trophic interactions in crustaceans (e.g. Hogan \& Griffen 2014, Griffen \& Norelli 2015), and these trophic changes in turn instigate changes in energy allocation to reproduction and energy storage (e.g. Griffen 2014, Belgrad \& Griffen 2016). All of this suggests that interactions leading to limb loss, resulting in altered foraging intake and subsequent modified energy allocation, could feasibly be influenced by human presence. If so, then we would expect that any potential tradeoff between limb regeneration and reproductive effort may vary with the level of human influence.

The mangrove tree crab Aratus pisonii is a marine neotropical species that is found abundantly associated with mangrove trees in the Atlantic from Brazil to Florida (Chace \& Hobbs 1969), though it has recently expanded into salt marshes due to climate change (Riley et al. 2014a). Subject to predation from birds and fish (Yeager et al. 2016), as well as conspecific aggression (Cannizzo et al. 2019), this species is known to readily employ autotomy as a habitatspecific anti-predator behavior (Johnston \& Smith 2018). Research over the last several years has provided considerable knowledge of the reproduction and energetics of this species, making it an ideal study system for examining the impacts of limb loss on reproduction and the tradeoff between regeneration and reproductive effort. Specifically, reproductive output (Riley et al. 2014b) and offspring quality (Riley \& Griffen 2017, Cannizzo et al. 2020) are both strongly influenced by diet quality in this primarily herbivorous crab. Crabs, and especially herbivorous crabs, are generally nitrogen-limited (Wolcott \& O'Connor 1992). Consequently, crabs that eat a lowerquality diet generally have a larger cardiac stomach than crabs that consume a higher-quality diet, where diet quality is determined largely by the proportion of the diet composed of animal tissue. This pattern is consistent both across species and within species (Griffen \& Mosblack 2011). Thus, long-term diet quality of individual crabs foraging in the field can be easily compared across crabs of different size using the ratio of gut width to carapace width (CW), as long as the gut grows isometrically with CW (Cannizzo et al. 2018, Griffen et al. 2018).

We used the injury status and reproductive effort of individual crabs to test the hypothesis that limb loss influences the amount and quality of food consumed. We tested this for both the loss of claws and the loss of walking legs because each may influence food consumption differently. Missing claws may have direct effects due to their use in foraging; they may also have indirect effects because missing claws reduce the ability to engage in intraspecific aggression and thus restrict access to foraging grounds (Warner 1970, Cannizzo et al. 2019), while walking legs may have indirect effects by hampering the ability of injured individuals to maneuver through mangrove canopies. We also test the hypothesis that the loss of walking legs or claws will reduce energy storage, either via reduced food intake or increased energy use for limb regeneration. We test the hypothesis that limb loss will reduce clutch size (defined here as the mass of the clutch of eggs), again either via reduced food intake or altered energy allocation. Further, we test these hypotheses using crabs collected from habitats that experience different levels of human use, thus allowing us to examine the influence of anthropogenic factors on diet and energy allocation. 
Finally, we directly test the hypothesis that there is a tradeoff between energy used to regenerate lost limbs and energy allocated to reproduction.

\section{MATERIALS AND METHODS}

\subsection{Crab collection}

We used crabs for this study that had been sampled for a separate study designed to examine the annual reproductive pattern of Aratus pisonii (J. Carver et al. unpubl. data). Consequently, samples were collected every few weeks throughout the portion of the year that encompassed the reproductive season. While this species reproduces yearround in tropical regions (Emmerson 1994), reproduction on the Florida coast where this study was conducted ranges from June to October (Cannizzo et al. 2020). We therefore collected adult female crabs from March through October. We focused on females because our hypotheses centered on theories of reproductive investment that were developed for females. Further, we collected crabs across 4 different sites that differed in the extent of anthropogenic influence (see next paragraph). In an effort to avoid depleting crabs at any 1 site, we rotated our sampling between these 4 sites that were chosen for accessibility and similarity. Table 1 provides coordinates and sampling dates for each of the sites. During each sampling period, we collected by hand the first 20 adult female crabs we encountered. Crabs were immediately placed on dry ice and kept frozen at $-80^{\circ} \mathrm{C}$ until dissection.

While the 4 sampling sites were similar in many ways (all were fringing mangrove habitats on the Intracoastal Waterway), there were some differences in the extent of anthropogenic influence across sites. North Causeway is next to a busy boat launch and is situated between a heavily traveled road and the Intracoastal Waterway and is therefore more heavily impacted by humans than our other sampling sites. Pepper Park and Round Island both abut mosquito impoundment embankments along the Intracoastal Waterway. Both are regularly used by fishermen and are located near popular boat launches in restricted speed zones but experience few additional human impacts. Oslo is the least disturbed of our sampling sites. It is a protected natural area located at the end of a gravel access road to a boat ramp that is not heavily used. This site has the most complete mangrove stand of our sample areas, transitioning into a hammock and a forest that separates it from the nearest major roadway.

\subsection{Crab dissections}

Frozen crabs were shipped on dry ice to Brigham Young University for dissection. Prior to dissection, we measured the $\mathrm{CW}$ of each crab to the nearest $0.1 \mathrm{~mm}$, noted any missing or regenerating limbs, and removed the egg clutch from the pleopods, if present. We then dissected crabs by first removing the dorsal carapace. We removed the ovaries, hepatopancreas, and gastric stomach and separately dried each of these and the egg mass to constant weight at $65^{\circ} \mathrm{C}$. We then weighed each to the nearest $0.01 \mathrm{mg}$. The width of the gastric stomach in brachyuran crabs is an indication of diet quality (Griffen \& Mosblack 2011), and the width increases isometrically with CW in this species $\left(\mathrm{p}<0.0001, \mathrm{R}^{2}=0.92\right)$. We therefore measured gut width to the nearest $0.1 \mathrm{~mm}$ and standardized this measure across crabs of different size by dividing gut width by CW. For the analyses described below (Section 2.3), we needed to know the mass of food in the gut independent of the mass of the gut wall. We therefore removed the mass of the gut wall itself by regressing the mass of the gut against CW for only those crabs that had empty stomachs upon dissection $(n=7)$. We then used this relationship (Gut wall $=0.003 \times \mathrm{CW}-0.044, \mathrm{p}=0.011$, $\mathrm{R}^{2}=0.71$ ) to determine the mass of the gut wall for each crab, which we then removed from the total gut mass, leaving only the mass of the consumed food.

Table 1. Sampling sites and dates $(\mathrm{d} / \mathrm{mo} / \mathrm{yr})$. Letters in parentheses following site names refer to the relative level of human impact at each site based on our qualitative assessment (see Section 2.1) (L: lowest impact; M: medium impact; H: highest impact)

\begin{tabular}{|c|c|c|c|c|}
\hline Site & Latitude, longitude & Sample period 1 & Sample period 2 & Sample period 3 \\
\hline Pepper Park (M) & $27^{\circ} 29^{\prime} 42^{\prime \prime} \mathrm{N}, 80^{\circ} 18^{\prime} 12^{\prime \prime} \mathrm{W}$ & $12 / 03 / 2018$ & $11 / 06 / 2018$ & 08/08/2018 \\
\hline North Causeway (H) & $27^{\circ} 28^{\prime} 28^{\prime \prime} \mathrm{N}, 80^{\circ} 19^{\prime} 12^{\prime \prime} \mathrm{W}$ & $13 / 04 / 2018$ & $26 / 06 / 2018$ & $20 / 08 / 2018$ \\
\hline Oslo Road (L) & $27^{\circ} 35^{\prime} 14^{\prime \prime} \mathrm{N}, 80^{\circ} 21^{\prime} 55^{\prime \prime} \mathrm{W}$ & $15 / 05 / 2018$ & $11 / 07 / 2018$ & $21 / 09 / 2018$ \\
\hline Round Island Park (M) & $27^{\circ} 33^{\prime} 33^{\prime \prime} \mathrm{N}, 80^{\circ} 19^{\prime} 53^{\prime \prime} \mathrm{W}$ & $25 / 05 / 2018$ & $25 / 07 / 2018$ & $23 / 10 / 2018$ \\
\hline
\end{tabular}


Finally, we also measured the dry mass to the nearest $0.1 \mu \mathrm{g}$ of 10 individual eggs from each gravid crab using a Metler Toledo XPR2U microbalance.

\subsection{Statistical analyses}

All statistical tests were conducted in $\mathrm{R}$, version 3.4.1 ( $\mathrm{R}$ Core Team 2014). We examined changes in the number of missing limbs with CW, collection site, and Julian sampling date using a generalized linear model (GLM) with a Poisson distribution. This was followed by a Tukey test to compare limb loss across specific sites. We then repeated this analysis using the number of limbs regenerating, as opposed to the number missing, as the response variable. We also used a GLM with a Poisson distribution to examine the number of limbs regenerating as a function of the number of limbs that were missing, using only the subset of crabs that had lost limbs.

We used linear models (LMs) to separately examine the impact of the number of missing limbs and the number of missing claws on the amount of food consumed (i.e. diet quantity), using the mass of the food in the gut as a proxy for the amount of food consumed. We initially included collection site and date in these models, but these were not significant and were removed.

We used LMs to separately examine changes in diet quality (standardized gut width) as a function of the number of limbs lost and the number of claws lost. We included both collection site and collection date in the model. Additionally, graphical inspection suggested that gut size changed nonlinearly with the number of missing limbs, and we therefore also included the squared term for the number of missing limbs (i.e. a polynomial second-order model for limb loss). We fit this model and all simpler models and then used Akaike's information criterion (AIC) to select the best-fitting model, which retained the linear and squared terms for the number of limbs lost and collection site, but not collection date.

We examined the influence of limb loss on energy storage using the mass of the hepatopancreas. As explained in Section 1, crabs generally accumulate long-term energy stores via lipids within the hepatopancreas. The mass of the hepatopancreas is expected to increase with crab size, and we therefore included $\mathrm{CW}$ in the model as a second explanatory variable. Collection site and date were initially included in the model, but did not explain a significant amount of the variation in hepatopancreas mass, and were removed. We also repeated this analysis using the number of claws missing and using the number of limbs regenerating rather than overall number of limbs missing.

We examined the influence of limb loss on reproduction in 4 separate ways. First, we used 2 separate GLMs with binomial distributions to determine whether the number of limbs that had been lost had any influence on whether or not crabs were ovigerous or vitellogenic (i.e. whether there was any total inhibition of reproduction). Second, we used a LM to examine the influence of limb loss on the overall mass of the clutch of eggs for crabs that were gravid. We also included CW in this analysis because egg mass is expected to increase with crab size. Third, we used a LM to examine the influence of limb loss on the mass of the ovary as a proxy for the influence of injury on future reproductive success. We again included CW because ovary mass should be expected to increase with crab size, and we also included whether or not a crab was vitellogenic, because crabs that are actively engaged in egg production should have larger ovaries. We also included collection site and date in both of these analyses, but these were not significant and were not included in the final models. Fourth, we used a linear mixed-effects model (LME) to examine the influence of limb loss on the mass of individual eggs (i.e. the per-propagule investment). We used crab ID as the random effect to control for repeated measures because we took 10 egg mass values for each individual crab. We again included $\mathrm{CW}$, collection site, and collection date in the model; however, the best-fitting model based on AIC retained only limb loss, CW, sampling date, and the interaction between CW and the number of limbs missing.

Lastly, we directly examined whether there is a tradeoff between energy allocation to limb regeneration and to reproduction. We did this by repeating the third analysis described in the preceding paragraph that examined the influence of limb loss on the mass of the ovary, but this time using the number of limbs regenerating as an independent variable rather than the number of limbs lost. A significant negative correlation between gonad mass and limb regeneration would provide direct evidence of an energetic tradeoff. We used the mass of ovaries in this analysis rather than the mass of eggs because the length of time that individual crabs may have been carrying eggs was uncertain. The time from egg production to hatching in A. pisonii is $14 \mathrm{~d}$ (García-Guerrero \& Hendrickx 2004), and the emergence of the early limb bud (the papilla) of a regenerating limb can occur as rapidly as 6-7 d after limb loss (Hopkins \& Das 2015). Thus, it is possible that a crab with an 
early limb bud could be carrying eggs that were produced prior to limb loss, obviating the need for any energetic tradeoff. It is similarly possible that by using the mass of the ovaries, a crab with an older limb bud could have regenerated this limb prior to energy allocation to the ovaries, again obviating the need for an energetic tradeoff. However, we deemed this less likely because the mean intermolt duration in female A. pisonii is $\sim 6 \mathrm{wk}$ (Díaz \& Conde 1989), and energetic investment to limb regeneration has 2 pulses, the initial pulse that produces the papilla shortly after limb loss and a final pulse just prior to molting (reviewed in Hopkins \& Das 2015). Additionally, ovary mass in this species generally increases at the start of the reproductive period in late spring and remains elevated until the end of the reproductive season in the fall because of the production of multiple clutches (B. D. Griffen unpubl. data). We therefore determined that the long-term nature of the elevated ovary mass was more likely to overlap with the period of energy contribution to limb regeneration, and was therefore more likely to display a tradeoff, if one exists.

\section{RESULTS}

Crabs at North Causeway were slightly smaller $(17.3 \pm 2.6 \mathrm{~mm} \mathrm{CW}$, mean $\pm \mathrm{SD})$, while the size of crabs at the other 3 sites did not differ $(18.3 \pm$ $2.5 \mathrm{~mm}$ ). However, as described above (Section 2.3), crab size was explicitly accounted for in each of the analyses that we conducted, and so this difference between sites does not bias the results reported here. We sampled 260 female crabs overall and found that $33.1 \%$ of these, or 86 crabs, were missing at least 1 limb. Overall there were $174,57,21,6,1$, and 1 crabs that were missing $0,1,2,3,4$, and 5 limbs, respectively. Of those that were missing limbs, 15 were missing at least 1 claw. The prevalence of injury was not influenced by crab size (Poisson GLM, $z_{254}=$ $-0.12, \mathrm{p}=0.90)$ nor by collection date $\left(z_{254}=0.24, \mathrm{p}=\right.$ 0.81 ). The number of limbs missing per crab was 0.73 \pm 1.01 (mean $\pm \mathrm{SD}$ ) at North Causeway, $0.48 \pm 0.68$ at Pepper Park, $0.45 \pm 0.86$ at Round Island, and $0.29 \pm$ 0.65 at Oslo. These differences were not significant between any of the sites $(p>0.2)$, except between North Causeway and Oslo (Tukey's post hoc, $z_{3,254}=$ $3.36, p=0.004)$. These results were nearly identical to the results when the number of limbs regenerating was analyzed. Specifically, limb regeneration was not influenced by crab size (Poisson GLM, $z_{254}=1.52$, $p=0.13)$ or by sampling date $\left(z_{254}=0.71, p=0.48\right)$, and there was an average of 1.1 more limbs regener- ating at North Causeway than at Oslo (Tukey's post hoc, $z_{3,254}=3.11, p=0.01$ ), but this was not different between any other sites $(p>0.10)$. The number of limbs regenerating increased with the number of limbs lost (Poisson GLM, $z_{85}=6.38, p<0.001$; Fig. 1), and overall, $59.4 \pm 9.3 \%$ of limbs that had been lost were in the process of regenerating.

There was no effect of limb loss on the amount of food that was consumed. This was true regardless of whether the model examined all limbs (LM, $t=1.74$, $p=0.08$ ) or just lost claws (lost claws treated as categorical rather than as numeric; $F_{2,257}=0.082, \mathrm{p}=$ 0.92).

The gut width, standardized for crab size, increased by $0.005 \pm 0.003 \mathrm{~mm}$ with each additional limb that was lost (LM, $t_{251}=2.22, \mathrm{p}=0.027$; Fig. 2), indicating that diet quality decreased with limb loss. While there appears to be a nonlinear trend in Fig. 2, this nonlinearity was not significant (LM second-order polynomial term, $t_{251}=-1.75, \mathrm{p}=0.082$ ). And while sample site was retained in the best-fitting model, there was no difference in gut width between sites after accounting for the effects of limb loss (all $\mathrm{p}>$ 0.05).

We found that energy storage, as indicated by the mass of the hepatopancreas, increased by $5.74 \pm$ $0.31 \mathrm{mg}$ for each $1 \mathrm{~mm}$ increase in CW $\left(\mathrm{LM}, t_{257}=\right.$ $18.63, \mathrm{p}<0.0001$ ), but was not influenced by the number of limbs that had been lost $\left(t_{257}=0.03, p=\right.$ $0.98)$. Given that the majority of lost limbs were being regenerated, these results were qualitatively identical when the number of limbs that had been lost was replaced by the number of limbs being regenerated $\left(\mathrm{LM}, t_{257}=0.46, \mathrm{p}=0.65\right)$.

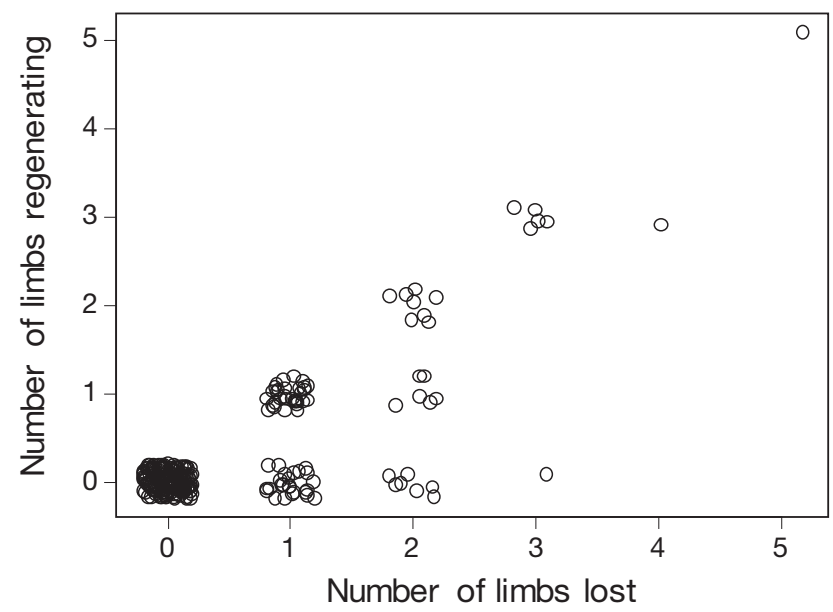

Fig. 1. Number of limbs regenerating as a function of the number of limbs that had been lost in Aratus pisonii. Values are jittered in both the $x$ and $y$ directions to avoid overlap of data points for presentation purposes only 


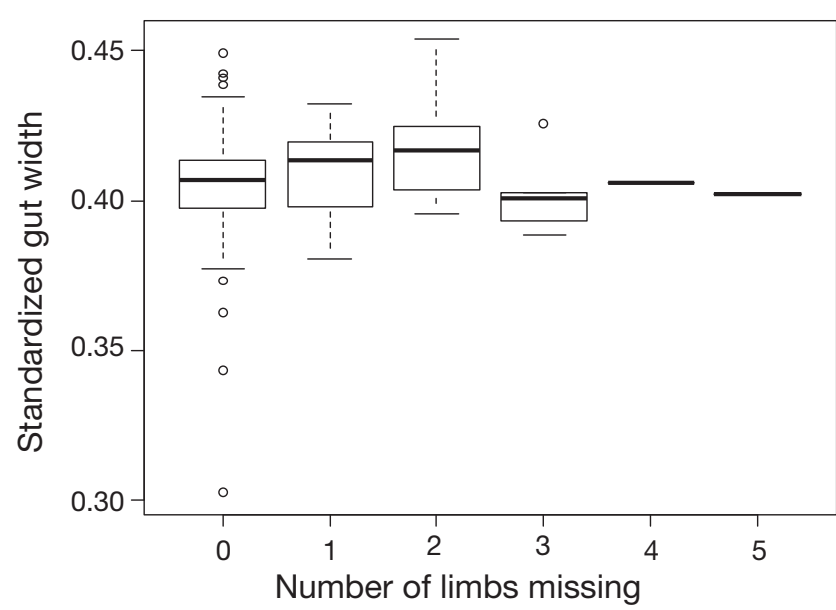

Fig. 2. Standardized gut width (a unitless metric), a proxy for long-term diet quality, as a function of the number of limbs that were missing in Aratus pisonii. Heavy line: sample median; box top and bottom: middle $50 \%$ of the data $\left(1^{\text {st }}-3^{\text {rd }}\right.$ quartiles); whiskers: $95 \%$ range; circles: outlier data points that fall outside this range

We found that while limb loss did have detrimental impacts on reproduction, limb loss did not seem to inhibit reproduction altogether. This was true both for the impact of limb loss on whether crabs were ovigerous (binomial GLM, $z_{258}=-0.09, \mathrm{p}=0.93$ ) and on whether they were vitellogenic (binomial GLM, $\left.z_{258}=-0.12, p=0.91\right)$. While there was not an effect at this strongest level (eliminating all reproductive effort), limb loss did have an effect at the intermediate level by reducing clutch size. Specifically, we found that the mass of the clutch of eggs increased by $11.16 \pm 0.69 \mathrm{mg}$ for each $1 \mathrm{~mm}$ increase in $\mathrm{CW}$ $\left(\mathrm{LM}, t_{120}=16.19, \mathrm{p}<0.0001\right)$, but decreased by $5.37 \pm$ $2.03 \mathrm{mg}$ for each additional limb that was lost $\left(t_{120}=\right.$ $-2.65, \mathrm{p}=0.009$; Fig. 3). Similarly, we found that limb loss also had detrimental impacts on future reproduction, as determined by the mass of the ovaries. Specifically, the mass of the ovary increased by $4.19 \pm 0.64 \mathrm{mg}$ for each $1 \mathrm{~mm}$ increase in CW (LM, $\left.t_{256}=6.55, \mathrm{p}<0.0001\right)$, was $22.28 \pm 4.80 \mathrm{mg}$ larger for crabs that were vitellogenic than for crabs that were not vitellogenic $\left(t_{256}=4.64, \mathrm{p}<0.0001\right)$, and decreased by $4.39 \pm 1.94 \mathrm{mg}$ for each additional limb that was lost $\left(t_{256}=-2.27, \mathrm{p}=0.024 ;\right.$ Fig. $\left.4 \mathrm{~A}\right)$.

The influence of limb loss on per-propagule investment was less clear. The overall mean mass of an individual egg was $7.6 \pm 1.7 \mu \mathrm{g}$. The mass of individual eggs increased by $0.14 \pm 0.05 \mu \mathrm{g}$ with each $1 \mathrm{~mm}$ increase in CW (LME, $t_{118}=2.78, \mathrm{p}=0.006$ ), and decreased by $0.006 \pm 0.003 \mu \mathrm{g}$ with each passing day during the reproductive season $(t=-2.19, \mathrm{p}=0.03)$. The number of missing limbs and the interaction

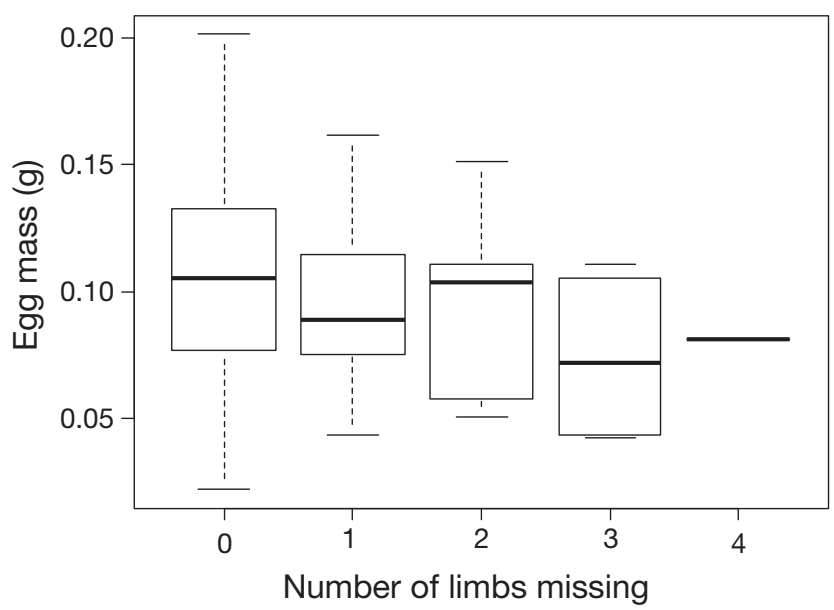

Fig. 3. Change in egg mass with each additional limb that was lost in Aratus pisonii. Box plots are as described in Fig. 2
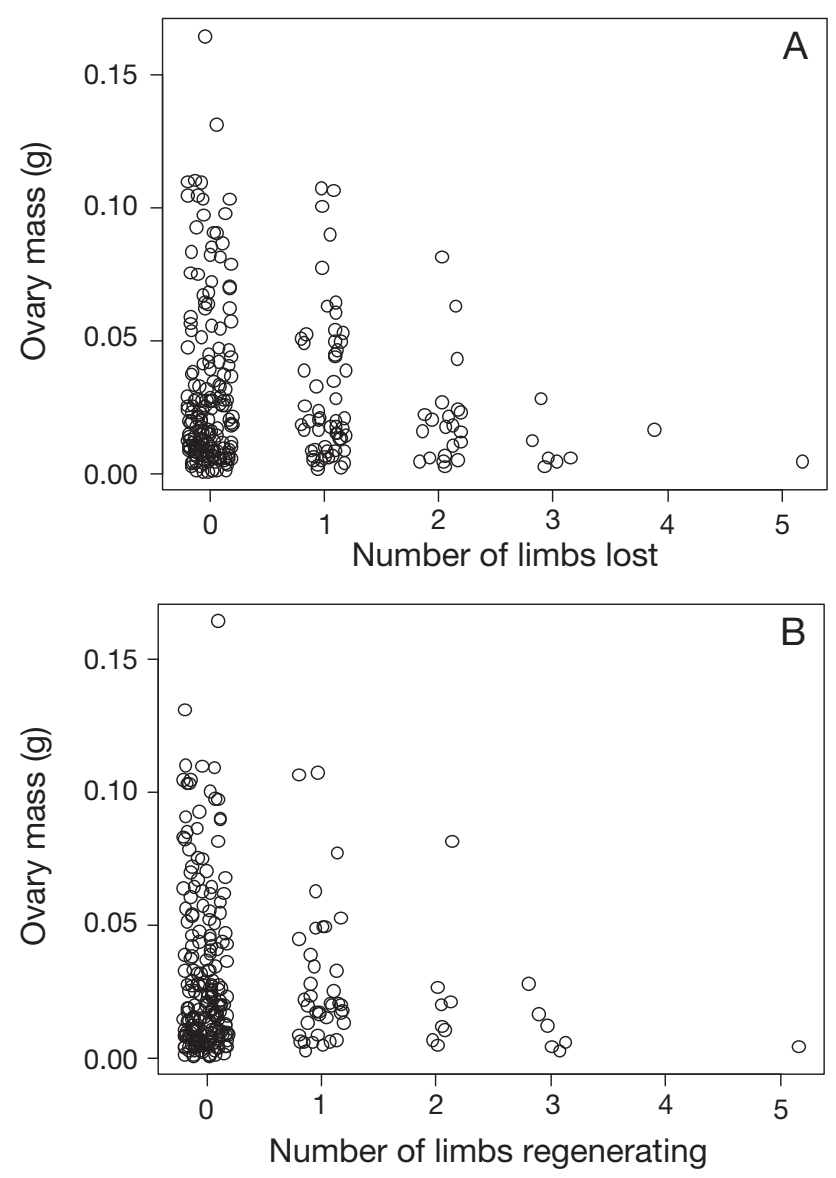

Fig. 4. Mass of the ovary as a function of (A) limb loss and (B) limb regeneration in Aratus pisonii. Values are jittered in the $x$ direction to avoid overlap of data points for presentation purposes only

between the number of missing limbs and CW were both included in the best-fitting model, but neither was significant (main effect: $t_{118}=1.78, \mathrm{p}=0.08$; 
interaction: $t_{118}=-1.87, \mathrm{p}=0.06$ ). Thus, the changes in clutch size with limb loss can be attributed primarily to reduced numbers of eggs produced, rather than to smaller egg sizes. If we therefore assume that the average egg size of $7.6 \pm 1.7 \mu \mathrm{g}$ does not change with limb loss, then these results indicate that the number of eggs produced in each clutch decreases by approximately $705 \pm 266$ eggs (mean \pm SD) for each additional limb that is lost. This represents from 3 to $15 \%$ of the total clutch size, depending on crab size.

Finally, we found a negative correlation between the mass of the ovaries and the number of limbs that were being regenerated by a crab, providing direct evidence for an energetic tradeoff. Specifically, we found that the mass of the ovary increased by $4.35 \pm$ $0.64 \mathrm{mg}$ for each $1 \mathrm{~mm}$ increase in CW (LM, $t_{256}=$ $6.77, \mathrm{p}<0.0001$ ), was $21.46 \pm 4.82 \mathrm{mg}$ larger for crabs that were vitellogenic than for crabs that were not vitellogenic $\left(t_{256}=4.46, \mathrm{p}<0.0001\right)$, and decreased by $5.13 \pm 2.29 \mathrm{mg}$ for each additional limb that was regenerating $\left(t_{256}=-2.24, \mathrm{p}=0.026\right.$; Fig. $\left.4 \mathrm{~B}\right)$.

\section{DISCUSSION}

We have demonstrated that limb loss, whether of walking legs or claws, does not reduce the amount of food consumed in mangrove tree crabs Aratus pisonii, while increased gut size in injured crabs suggests that the quality of consumed food declines as the number of limbs lost increases. We have further shown that limb loss and regeneration has no measurable impact on the mass of energy (lipids) stored in the hepatopancreas, but that there are clear reproductive consequences of limb loss. Specifically, we did not find any evidence that reproduction ceased following limb loss. However, we did find that egg mass (current reproduction) and ovary mass (future reproduction) both declined as the number of missing limbs increased. The absence of any clear change in egg size with limb loss suggests that these reductions in egg/ovary mass primarily reflect the production of fewer eggs rather than a change in bulk perpropagule investment. Thus, the impacts of limb loss in this species appear to be of intermediate intensity based on the scale proposed by Bernardo \& Agosta (2005). Finally, we found direct evidence of an energetic tradeoff between limb regeneration and reproductive effort.

This was an observational study and therefore cannot prove cause and effect. Rather than limb loss causing reduced reproductive success, it is therefore possible that the reverse is true, that poor-quality individuals with low reproductive potential also happen to lose more limbs. However, we struggle to find a feasible explanation for this interpretation. In contrast, there is a clear mechanistic explanation, supported by the results presented here, for the interpretation that limb loss reduces reproductive success - specifically, that limb loss alters food consumption in ways that reduce the quality of food consumed, which is known to reduce reproductive effort in this species (Riley et al. 2014b). At the same time, the energy and nutrients required for limb regeneration cannot be used for reproduction, thus causing a tradeoff between allocation to these 2 processes.

These findings are consistent with other patterns in reproductive variation for this species. This species has colonized salt marsh habitats in northern Florida and Georgia as a result of its climate-induced northward range expansion (Riley et al. 2014a). Additionally, some marsh crabs have adopted a strategy of residing on boat docks, an anthropogenic habitat that provides improved thermal and dietary conditions compared to the surrounding marsh (Cannizzo et al. 2018). Along with these habitat shifts have come changes in the diet. Crabs on boat docks consume a considerable amount of animal material and this higher-quality food is reflected in a median standardized gut width that is approx. 0.01 units smaller than crabs in the mangrove. Meanwhile, crabs in a salt marsh consume lower-quality detritus and marsh grass and have a median standardized gut width that is approx. 0.01 units larger than crabs in the mangrove (Cannizzo et al. 2018). Results here show that the median standardized gut width increases by approx. 0.01 units for each lost limb (at least for the first 2 limbs lost), suggesting that the dietary impacts of limb loss are equivalent to the dietary impacts of habitat shifts that have taken place in this species.

Impacts of limb loss on reproduction can also be compared to changes in reproduction that accompany the range shift into salt marshes, a habitat that presents crabs with suboptimal dietary and thermal conditions (Cannizzo et al. 2018). Crabs in a salt marsh do not alter the size of individual eggs relative to conspecifics in the mangrove (Riley \& Griffen 2017) and the mass-specific bulk energy of eggs does not differ between habitats (Cannizzo et al. 2020), consistent with the constant per-propagule investment for injured and uninjured crabs shown here. This suggests that in this species, bulk energy investment into individual propagules may be a fixed strategy. However, while the bulk investment may remain constant, the lipid content and fatty acid composition 
of eggs differs by habitat and seems to be associated with diet (Cannizzo et al. 2020), resulting in lowerquality offspring from poorer habitats (Riley \& Griffen 2017, Cannizzo et al. 2020). Reductions in diet quality with limb loss could similarly alter larval quality, which would constitute a lower per-propagule investment for injured crabs, but this hypothesis remains to be tested. While there was no change in egg size with limb loss, we found that clutch mass did decrease with limb loss. If we used the mean mass of individual eggs reported here $(7.6 \mu \mathrm{g})$, this reduced clutch mass is equivalent to a reduction in clutch size of $705 \pm 266$ eggs for each additional limb lost. And presumably this lost reproduction would be repeated for each clutch until limbs are regenerated. While not trivial, this is much smaller than the variation in clutch size documented across mangrove, marsh, and dock habitats (Cannizzo et al. 2020). Further, at the population level, based on the size distribution of crabs sampled here, this would result in only a modest $2.5 \%$ decrease in the number of eggs produced.

There has been a general paucity of studies on the reproductive consequences of limb loss that take a quantitative approach, showing the impact of each additional limb that is lost rather than simply treating injury as a binary variable. Here we only examined 1 type of impact on reproduction - the impacts on actual reproductive products. Other aspects are also known to be important, such as the impacts of limb loss on ritualistic interactions that occur between individuals of this species during general encounters (Warner 1970, Cannizzo et al. 2019) and potentially for reproductive interactions (Christy 1987). We also did not look at mechanisms of energetic constraints. Claw loss can strongly alter food consumption in crabs (reviewed in Juanes \& Smith 1995). We found that gut size increased following limb loss, suggesting that diet quality decreased (Griffen \& Mosblack 2011). It is unclear just how much of the reduced reproduction with limb loss was due to dietary aspects and how much was due to energetic tradeoffs in energy allocation. However, we found no change in energy storage (hepatopancreas mass) with limb loss, and the cost of energy storage can be considerable, even in these small-bodied ectotherms (Griffen 2017). Thus, maintaining energy stores on a diet of reduced quality may present a considerable metabolic challenge and could be a factor contributing to reduced reproductive effort following injury.

The negative consequences of limb loss on reproduction reported here may be common across crustacean species, as similar trends have been reported by previous studies where this question was explored
(Norman \& Jones 1993, Melville-Smith \& de Lestang 2007, Hobbs et al. 2017, Crowley et al. 2019). However, this represents a very small number of studies, and more are needed that quantitatively examine this relationship across a variety of systems. The impacts of limb loss on reproduction could have important consequences for species that are captured commercially. Capture and handling of commercial species can inadvertently lead to limb loss (e.g. Leland et al. 2013), while in claw-based fisheries, the removal of claws is the principal goal of the fishery. In both of these cases, limb loss can lead to substantial mortality (Duermit et al. 2017) with direct population-level consequences. But limb loss may additionally have indirect population level consequences via reduced reproductive performance following limb loss. If the decrease is minor, as reported here for $A$. pisonii, then reproductive consequences may be small relative to other factors that also influence reproduction and population growth rate. But additional research is needed to determine whether the small impacts reported here are common across other species.

Finally, while the differences were not all significant, we found the highest level of injury per crab at the most disturbed site (North Causeway), the lowest level of injury at the least disturbed site (Oslo), and intermediate levels at the sites with intermediate disturbance. The field of marine urban ecology is a nascent area of investigation (Malerba et al. 2019, Todd et al. 2019) and it remains unclear how urbanization and human impacts in highly populated areas influence the health of individual organisms in the marine environment. In terrestrial systems, it has been seen that the health of individual organisms is lower in urbanized areas and higher in rural or wild areas (Murray et al. 2019). While the differences here were not significant across all sites, they are suggestive that, as in terrestrial environments, human impacts in marine environments also lead to greater injury or reduced health of individual organisms.

Acknowledgements. This is Smithsonian Marine Station contribution number 1132.

\section{LITERATURE CITED}

Adiyodi RG (1969) On the storage and mobilization of organic resources in the hepatopancreas of a crab (Parathelphusa hydrodromus). Experientia 25:43-44

Barrios JV, Gaymer CF, Vásquez JA, Brokordt KB (2008) Effect of the degree of autotomy on feeding, growth, and reproductive capacity in the multi-armed sea star Heliaster helianthus. J Exp Mar Biol Ecol 361:21-27 
Belgrad BA, Griffen BD (2016) The influence of diet composition on the fitness of the blue crab, Callinectes sapidus. PLOS ONE 11:e0145481

*Bernardo J, Agosta SJ (2005) Evolutionary implications of hierarchical impacts of nonlethal injury on reproduction, including maternal effects. Biol J Linn Soc 86:309-331

Bingham BL, Burr J, Head HW (2000) Causes and consequences of arm damage in the sea star Leptasterias hexactis. Can J Zool 78:596-605

Boudreau SA, Worm B (2012) Ecological role of large benthic decapods in marine ecosystems: a review. Mar Ecol Prog Ser 469:195-213

Brock RE, Smith LD (1998) Recovery of claw size and function following autotomy in Cancer productus (Decapoda: Brachyura). Biol Bull (Woods Hole) 194:53-62

Caldwell RL (2005) An observation of inking behavior protecting adult Octopus bocki from predation by green turtle (Chelonia mydas) hatchlings. Pac Sci 59:69-72

Cannizzo ZJ, Dixon SR, Griffen BD (2018) An anthropogenic habitat within a suboptimal colonized ecosystem provides improved conditions for a range-shifting species. Ecol Evol 8:1521-1533

* Cannizzo Z, Nix S, Whaling I, Griffen B (2019) Individual morphology and habitat structure alter social interactions in a range-shifting species. Diversity (Basel) 11:6

Cannizzo ZJ, Lang SQ, Benitez-Nelson B, Griffen BD (2020) An artificial habitat increases the reproductive fitness of a range-shifting species within a newly colonized ecosystem. Sci Rep 10:554

Chace FA, Hobbs HH (1969) The freshwater and terrestrial decapod crustaceans of the West Indies with special reference to Dominica. Bull US Natl Mus 292:1-258

Chapple DG, Swain R (2004) Inter-populational variation in the cost of autotomy in the metallic skink (Niveoscincus metallicus). J Zool 264:411-418

Christy JH (1987) Competitive mating, mate choice and mating associations of brachyuran crabs. Bull Mar Sci 41: 177-191

Cooper WE Jr, Frederick WG (2009) Predator lethality, optimal escape behavior, and autotomy. Behav Ecol 21:91-96

* Crowley CE, Shea CP, Gandy RL, Daly KL (2019) Fecundity assessment of stone crabs in the eastern Gulf of Mexico. Mar Coast Fish 11:32-47

* Daleo P, Luppi T, Casariego AM, Escapa M, Ribeiro P, Silva P, Iribarne O (2009) The effect of size and cheliped autotomy on sexual competition between males of the mud crab Cyrtograpsus angulatus Dana. Mar Biol 156: 269-275

De Vlas J (1979) Annual food intake by plaice and flounder in a tidal flat area in the Dutch Wadden Sea, with special reference to consumption of regenerating parts of macrobenthic prey. Neth J Sea Res 13:117-153

Díaz H, Conde JE (1989) Population dynamics and life history of the mangrove crab Aratus pisonii (Brachyura, Grapsidae) in a marine environment. Bull Mar Sci 45: 148-163

Diaz-Guisado D, Gaymer CF, Brokordt KB, Lawrence JM (2006) Autotomy reduces feeding, energy storage and growth of the sea star Stichaster striatus. J Exp Mar Biol Ecol 338:73-80

Donihue M (2018) Lobsters to dollars: the economic impact of the lobster distribution supply chain in Maine. Final report to Maine State Department of Marine Resources. Colby College, Waterville, ME

* Duermit E, Shervette V, Whitaker JD, Kingsley-Smith PR,
Wilber D (2017) A field assessment of claw removal impacts on the movement and survival of stone crabs Menippe spp. Fish Res 193:43-50

Emberts Z, Escalante I, Bateman PW (2019) The ecology and evolution of autotomy. Biol Rev Camb Philos Soc 94: 1881-1896

*Emmerson WD (1994) Seasonal breeding cycles and sex ratios of eight species of crabs from Mgazana, a mangrove estuary in Transkei, Southern Africa. J Crustac Biol 14:568-578

Fleming PA, Muller D, Bateman PW (2007) Leave it all behind: a taxonomic perspective of autotomy in invertebrates. Biol Rev Camb Philos Soc 82:481-510

*Gandy R, Crowley C, Chagaris D, Crawford C (2016) The effect of temperature on release mortality of declawed Menippe mercenaria in the Florida stone crab fishery. Bull Mar Sci 92:1-5

* García-Arrarás JE, Díaz-Miranda L, Torres II, File S and others (1999) Regeneration of the enteric nervous system in the sea cucumber Holothuria glaberrima. J Comp Neurol 406:461-475

* García-Guerrero M, Hendrickx ME (2004) Embryology of decapod crustaceans I. Embryonic development of the mangrove crabs Goniopsis pulchra and Aratus pisonii (Decapoda: Brachyura). J Crustac Biol 24:666-672

*Gerald GW, Thiesen KE (2014) Locomotor hindrance of carrying an enlarged sexually selected structure on inclines for male fiddler crabs. J Zool (Lond) 294:129-138

Griffen BD (2014) Linking individual diet and fecundity in an omnivorous marine consumer. Oecologia 174:121-130

* Griffen BD (2017) Metabolic costs of capital energy storage in a small-bodied ectotherm. Ecol Evol 7:2423-2431

Griffen BD (2018) The timing of energy allocation to reproduction in an important group of marine consumers. PLOS ONE 13:e0199043

Griffen BD, Mosblack H (2011) Predicting diet and consumption rate differences between and within species using gut ecomorphology. J Anim Ecol 80:854-863

Griffen BD, Norelli AP (2015) Spatially variable habitat quality contributes to within-population variation in reproductive success. Ecol Evol 5:1474-1483

* Griffen BD, Cannizzo ZJ, Gül MR (2018) Ecological and evolutionary implications of allometric growth in stomach size of brachyuran crabs. PLOS ONE 13:e0207416

* Hancock ER, Griffen BD (2017) Energetic consequences of temperature and sequential autotomization for the stone crab, Menippe spp. Mar Ecol Prog Ser 582:133-146

*Hobbs NV, Cobb JS, Thornber CS (2017) Injury, reproductive status, and distribution of Hemigrapsus sanguineus (De Haan, 1835) (Brachyura: Varunidae) on the rocky intertidal shores of Rhode Island, USA. J Crustac Biol 37 : $16-20$

* Hogan JM, Griffen BD (2014) The dietary and reproductive consequences of fishery-related claw removal for the stone crab Menippe spp. J Shellfish Res 33:795-805

Hopkins PM, Das S (2015) Regeneration in crustaceans. In: Chang ES, Thiel M (eds) The natural history of the Crustacea, Vol 4: Physiology. Oxford University Press, New York, NY, p 168-198

* Johnston CA, Smith RS (2018) Vegetation structure mediates a shift in predator avoidance behavior in a rangeedge population. Behav Ecol 29:1124-1131

Juanes F, Smith LD (1995) The ecological consequences of limb damage and loss in decapod crustaceans: a review and prospectus. J Exp Mar Biol Ecol 193:197-223 
Kern JM, Radford AN (2016) Anthropogenic noise disrupts use of vocal information about predation risk. Environ Pollut 218:988-995

Kirkpatrick M, Lande R (1989) The evolution of maternal characters. Evolution 43:485-503

Leland JC, Butcher PA, Broadhurst MK, Paterson BD, Mayer DG (2013) Damage and physiological stress to juvenile eastern rock lobster (Sagmariasus verreauxi) discarded after trapping and hand collection. Fish Res 137:63-70

Lindsay SM (2010) Frequency of injury and the ecology of regeneration in marine benthic invertebrates. Integr Comp Biol 50:479-493

Maginnis TL (2006) The costs of autotomy and regeneration in animals: a review and framework for future research. Behav Ecol 17:857-872

Malerba ME, White CR, Marshall DJ (2019) The outsized trophic footprint of marine urbanization. Front Ecol Environ 17:400-406

Mcgaw IJ (2006) Cardiovascular and respiratory responses associated with limb autotomy in the blue crab, Callinectes sapidus. Mar Freshw Behav Physiol 39: 131-141

Melville-Smith R, de Lestang S (2007) Changes in egg production of the western rock lobster (Panulirus cygnus) associated with appendage damage. Fish Bull 105: 418-426

Miller JA, Byrne M (2000) Ceratal autotomy and regeneration in the aeolid nudibranch Phidiana crassicornis and the role of predators. Invertebr Biol 119:167-176

Molfese C, Beare D, Hall-Spencer JM (2014) Overfishing and the replacement of demersal finfish by shellfish: an example from the English Channel. PLOS ONE 9: e101506

Murray MH, Sánchez CA, Becker DJ, Byers KA, WorsleyTonks KE, Craft ME (2019) City sicker? A meta-analysis of wildlife health and urbanization. Front Ecol Environ $17: 575-583$

Norman CP, Jones MB (1993) Reproductive ecology of the velvet swimming crab, Necora puber (Brachyura: Portunidae), at Plymouth. J Mar Biol Assoc UK 73:379-389

Peterson $\mathrm{CH}$, Quammen ML (1982) Siphon nipping: its importance to small fishes and its impact on growth of the bivalve Protothaca staminea (Conrad). J Exp Mar Biol Ecol 63:249-268

Purcell JE (1977) Aggressive function and induced development of catch tentacles in the sea anemone Metridium senile (Coelenterata, Actinaria). Biol Bull (Woods Hole) 153:355-368

R Core Team (2014) R: a language and environment for statistical computing. R Foundation for Statistical Computing, Vienna. www.R-project.org

Reichmuth JM, Roudez R, Glover T, Weis JS (2009) Differences in prey capture behavior in populations of blue crab (Callinectes sapidus Rathbun) from contaminated and clean estuaries in New Jersey. Estuar Coasts 32: 298-308

Riley ME, Griffen BD (2017) Habitat-specific differences

Editorial responsibility: James McClintock,

Birmingham, Alabama, USA alter traditional biogeographic patterns of life history in a climate-change induced range expansion. PLOS ONE 12:e0176263

Riley ME, Johnston CA, Feller IC, Griffen BD (2014a) Range expansion of Aratus pisonii (mangrove tree crab) into novel vegetative habitats. Southeast Nat 13:N43-N48

* Riley ME, Vogel M, Griffen BD (2014b) Fitness-associated consequences of an omnivorous diet for the mangrove tree crab Aratus pisonii. Aquat Biol 20:35-43

* Schwagmeyer PL, Mock DW (2008) Parental provisioning and offspring fitness: size matters. Anim Behav 75: 291-298

Smith LD (1992) The impact of limb autotomy on mate competition in blue crabs Callinectes sapidus Rathbun. Oecologia 89:494-501

Stearns SC (1989) Trade-offs in life-history evolution. Funct Ecol 3:259-268

Steneck RS (1997) Fisheries-induced biological changes to the structure and function of the Gulf of Maine ecosystem. In: Wallace GT, Braasch EF (eds) Proceedings of the Gulf of Maine ecosystem dynamics, scientific symposium and workshop. RARGOM Report 91-1. RARGOM, Hanover, NH, p 151-165

Steneck RS, Carlton JT (2001) Human alterations of marine communities: students beware! In: Bertness MD, Gaines SD, Hay ME (eds) Marine community ecology. Sinauer Associates, Sunderland, MA, p 445-468

* Todd PA, Heery EC, Loke LH, Thurstan RH, Kotze DJ, Swan C (2019) Towards an urban marine ecology: characterizing the drivers, patterns and processes of marine ecosystems in coastal cities. Oikos 128:1215-1242

* Tummon Flynn PS, Mellish CL, Pickering TR, Quijón PA (2015) Effects of claw autotomy on green crab (Carcinus maenas) feeding rates. J Sea Res 103:113-119

* Tyler RK, Winchell KM, Revell LJ (2016) Tails of the city: caudal autotomy in the tropical lizard, Anolis cristatellus, in urban and natural areas of Puerto Rico. J Herpetol 50: 435-441

Vonk HJ (1960) Digestion and metabolism. In: Waterman TH (ed) The physiology of Crustacea, Vol 1. Academic Press, New York, NY, p 281-316

Warner GF (1970) Behaviour of two species of grapsid crabs during intraspecific encounters. Behaviour 36:9-19

Warner GF (1977) The biology of crabs. Scientific Books, London

WWasson K, Lyon BE, Knope M (2002) Hair-trigger autotomy in porcelain crabs is a highly effective escape strategy. Behav Ecol 13:481-486

Wolcott DL, O'Connor NJ (1992) Herbivory in crabs: adaptations and ecological considerations. Am Zool 32:370-381

Wolin EM, Laufer H, Albertini DF (1973) Uptake of the yolk protein, lipovitellin, by developing crustacean oocytes. Dev Biol 35:160-170

Y Yeager LA, Stoner EW, Peters JR, Layman CA (2016) A terrestrial-aquatic food web subsidy is potentially mediated by multiple predator effects on an arboreal crab. J Exp Mar Biol Ecol 475:73-79

Submitted: December 16, 2019; Accepted: March 2, 2020

Proofs received from author(s): March 30, 2020 